\title{
Evaluation of the Nutritional Supplement VIUSID Vet Powder on the Productive Behaviour of Sows and Boars
}

\author{
Juan Carlos Rodríguez-Fernández ${ }^{1}$, Vicente Méndez-García ${ }^{1}$, Ibraín Calero-Herrera ${ }^{1}$, Kolima Peña-Calzada ${ }^{1}$, \\ Domingo Martos-Tejera ${ }^{2}$ and Bulent Kukurtcu ${ }^{3}$ \\ 1. Department of Veterinary Medicine and Animal Husbandry, University of Sancti Spiritus, Sancti Spiritus 60100, Cuba \\ 2. Department of Production, Swine Farm of Venega, Yaguajay 64180, Cuba \\ 3. Scientific Department, CATALYSIS, S.L., Madrid 28016, Spain
}

\begin{abstract}
The objective of this research was to evaluate the effect of administering VIUSID vet powder on the productive behaviour of sows and the quality of semen of boars. Two experiments were conducted on farms in the province of Sancti Spiritus, in the central region of Cuba. One was with sows, starting 21 days before parturition until weaning, and another was with boars in directed mounting. Each sow received 10 grams of VIUSID vet powder everyday, mixed with food, from 21 days before the probable date of farrowing and until weaning (33-day lactation period). In the boars, the treatment consisted of administering 10 grams of VIUSID vet powder with feed, once a day for 6 weeks (week 1 to 6); from week 7 onwards, the supplement was suspended. Results showed that, supplying VIUSID vet powder significantly improved the principal post-partum productivity indicators and significantly reduced diarrhoea and administration to boars in production for 6 weeks, which has improved spermatic motility and does not affect the other variables representative of the quality of the semen.
\end{abstract}

Key words: VIUSID, sows, boars, Glycyrrhizaglabra.

\section{Introduction}

It is evident that nutrition plays a key role in the reproduction of all superior animal species. In general, species have adjusted their reproductive cycles to the available food resources, and animal physiology has adapted in order to satisfy the nutritional requirements related to reproduction. In domestic species, and in particular for pigs, this adaptation has been deeply altered over the years based on the improvements obtained in the genetic lines, food programs, handling and health. In any swine farm, the productive behaviour of the breeders (males and females) is a determining factor in results, and this depends, to a large extent, on proper nutrition.

The sows' feed has to be supplemented in the last third of gestation, especially the protein and vitamin-mineral content, which positively influences

Corresponding author: Juan Carlos Rodríguez-Fernández, Ph.D., main research field: animal nutrition. the survival rate of the piglets in the first days of life due to their higher farrowing weight [1].

It has been proven that reproductive function is influenced by diverse factors: climatic, handling, nutritional and health being among the most important. These factors can act negatively on the spermatic production of boar, causing certain quantitative and qualitative changes that have an impact, in the short term, on a decrease in the productivity of the boar [2].

During the semen collection regime, the boar has different nutritional demands than growing and fattening pigs. Maintaining spermatogenesis requires an input of energy and protein on different levels, as well as macro and micro elements that may be limiting [3].

To improve the productive behaviour of sows and boars, different food additives are used and evaluated to help meet their nutritional requirements, but it is of interest that they are safe for people and the environment. 
For many years, antimicrobials have been used as feed additives, but due to concerns that their use in nutrition may contribute to an increase in bacterial resistance, the European Union decided to ban them as additives on the 1st of January 2006. Therefore, many alternatives to establish other substances with similar beneficial effects have started to be evaluated since [4].

The nutritional supplement VIUSID vet powder includes among its components amino acids, vitamins, minerals, and glycyrrhizinic acid, which is an extract from the root of the liquorice (Glycyrrhiza glabra) plant. It is a substance with antibacterial and antiviral properties, thus constituting an excellent alternative to the use of antimicrobial agents to improve production without the disadvantage of resting times or the presence of chemical residue [5]. Its components are subjected to a process of molecular activation, which allows favourable results in animal farming without affecting people and the environment using minimal doses [6].

The objective of this research was to evaluate the effect of administering VIUSID vet powder on the productive behaviour of sows and the quality of semen of boars.

\section{Approach and Research Methods}

\subsection{General Aspects}

Two experiments were conducted on farms in the province of Sancti Spiritus, in the central region of Cuba. One was with sows, starting 21 days before parturition until weaning, and another was with boars in directed mounting.

The supplement evaluated in both trials was VIUSID vet powder, which contains Malic acid, glucosamine, arginine, glycine, ascorbic acid, folic acid, monoammonium glycyrrhizinate (Glycyrrhiza glabra root extract), pyridoxine hydrochloride, cyanocobalamin, and calciumpantothenate and zinc sulphate. In addition, its components are subjected to a biocatalytic process of molecular activation to improve their biological activity and the biochemical reactivity of all its molecules, without affecting their molecular structure.

\subsection{Approach and Research Methods of Experiment 1}

The experiment was carried out at the Cabaiguan Swine Genetics Centre, located in the municipality that has the very same name, in the province of Sancti Spíritus (Cuba). The coordinates are $22^{\circ} 04^{\prime} 00.21^{\prime \prime} \mathrm{N}$ and $79^{\circ} 30^{\prime} 30.72^{\prime \prime}$ 'W.

A totally randomized group comparison design was used for the experiment. Two homogeneous groups of gestated sows (between second and fifth farrowing) were formed, with 35 sows in the control group and 37 in the treated group. Each sow daily received 10 grams of VIUSID vet powder, mixed with food, from 21 days before the probable date of farrowing and until weaning (33-day lactation period).

Variables under analysis:

(1) Independent: The treatments with VIUSID vet powder.

(2) Dependent: Piglets born alive per litter (PBA), stillborn piglets per litter (SPL), piglets weaned per litter (PWL), litter weight at farrowing (Initial weight, $\mathrm{kg}$ ), litter weight at weaning (Final weight, $\mathrm{kg}$ ), increase of weight per litter (Increase of weight, $\mathrm{kg}$ ), weaning-fecundationinterval (WFI), incidence of diarrhoea in piglets $(\%)$, mortality of piglets (\%) and body condition of the sow at weaning (BC). For the estimation of body condition, the methodology recommended by Brooks and Cole [7] was used.

Statistical analysis: Previously, normal distribution of data was evaluated using the Kolmogorov-Smirnov test for goodness of fit, and the Levene test was applied to evaluate the homogeneity of variance. Except the variables incidence of diarrhoea and mortality, that were analysed using the hypothesis test for proportions (MINITAB statistical package release 14.12.0 [8]), the others were processed using the T-test (Student's t-test) for data with homogeneity of variance using the SPSS 15.0.1 statistical package for Windows [9]. 


\subsection{Approach and Research Methods of Experiment 2}

The experiment was performed at the Venegas pig farm, located in the municipality of Yaguajay, province of Sancti Spiritus (Cuba), at coordinates: $22^{\circ} 10^{\prime} 08.99^{\prime \prime} \mathrm{N}$ and 7909'12" W.

A totally randomized group comparison design was used for the experiment. Two groups were formed, each with 12 boars of similar age, genotype and spermatic quality. The clinical trial lasted 98 days. The treatment consisted in administering 10 grams of VIUSID vet powder with feed to each animal, once a day for 6 weeks (week 1 to 6); from week 7 onwards the supplement was suspended. The other group was used as control.

Evaluations were carried out at three points: at the beginning of the experiment (week 1), 8 weeks after the start of the experiment (week 9) and in the last week of the experiment (week 14).

Variables under analysis:

(1) Independent: The treatment with VIUSID vets Powder.

(2) Dependent: Volume of ejaculate $(\mathrm{ml})$, spermatic concentration $\left(10^{6} \mathrm{spz} / \mathrm{mL}\right)$, spermatozoa motility (\%), $\mathrm{pH}$, normal and pathological sperm (\%) and colour and odour of semen. The determinations were made as indicated by the Technical Procedures Manual for the pig industry in Cuba [10].
Statistical analysis: Previously, normal distribution of data was evaluated using the Kolmogorov-Smirnov test for goodness of fit, and the Levene test was applied to evaluate the homogeneity of variance. Except the variables normal sperm, pathological sperm, colour of the semen and odour of semen, that were processed using the hypothesis test for proportions (MINITAB statistical package release 14.12.0 [8]), the others were processed using the T-test for data with homogeneity of variance using the SPSS 15.0.1 statistical package for Windows [9].

\section{Results and Discussion}

\subsection{Results and Discussion of Experiment 1}

Fig. 1 shows the percentage of piglets that had diarrhoea. The group in which the sow received VIUSID from 21 days before the probable date of farrowing showed a significant reduction $(\mathrm{p}<0.05)$, $7.58 \%$ less than the control group.

It is well known that the diarrhoea affects animal growth and feed efficiency. Enteric diseases, and in particular diarrhoeas of an infectious nature, represent one of the most common problems in pigs from their farrowing until the fattening stage. The emergence of these diseases is generated by the interaction of three key elements: the presence of enteric pathogens at the farm, the conditions of hygiene and handling, and the

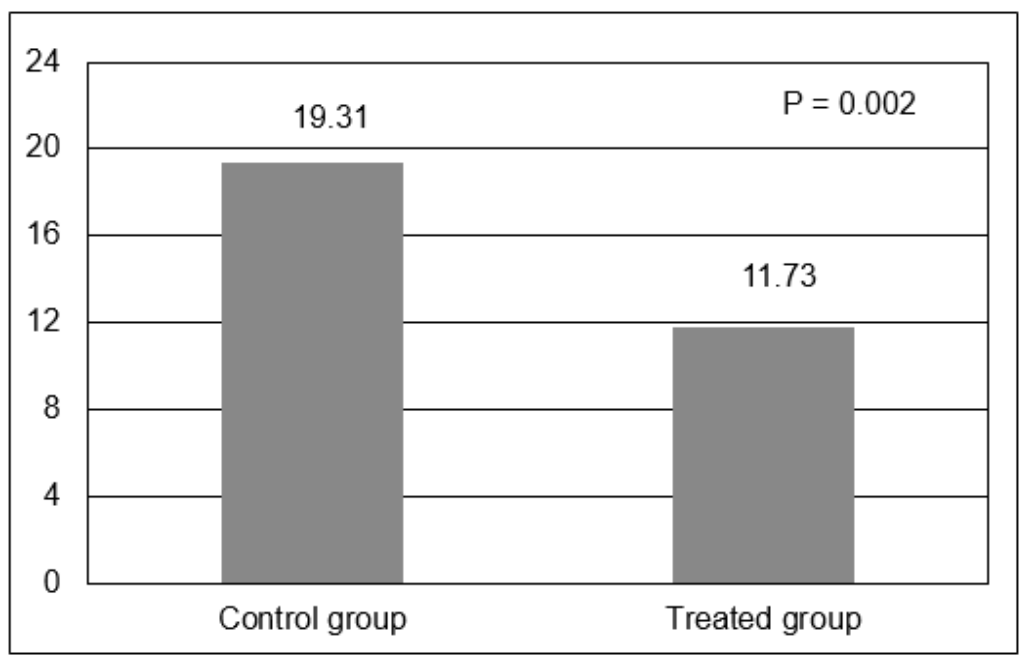

Fig. 1 Effect of VIUSID vet powder on the presence of diarrhoea in piglets (\%). 
immunity of the pigs against pathogens circulating in the farm. This final aspect is critical and of special importance in the diarrhoeas of lactating piglets and upon weaning [11].

VIUSID has immunomodulatory properties which must have been an influencing factor in a better immune status of the sow and therefore of its offspring. In the first weeks of life, the piglet fundamentally depends on the immunity transferred to it from its mother through the colostrum for protection, leading to the lower incidence of diarrhoea in the treated group.

In newly weaned pigs significant reductions in diarrhoeas were reported $(p<0.05)$, when treated with doses of $1,1.5$ and 2 grams of VIUSID vet powder, when compared with those not treated [12].

At the end of gestation, the role of the anti-oxidant "cocktails" becomes relevant to the immunity of the sow, the quality of the colostrum, the vigour of the piglets and the prevention of splay leg, particularly associated to the lecithins that would improve absorption. We must also take into account the vitamin B12, the need for which is very underestimated by the NRC $(0.5 \mathrm{mg} / \mathrm{kg})$ and which is completely absent in the vegetable rations [13].

Diarrhoea in pigs is often due to rotavirus. The components of VIUSID confer immunomodulatory and antiviral properties, very important to counteract infectious diseases. One of the components is monoammonium glycyrrhizinate, which has an antiviral action proven in previous studies with people $[14,15]$.

Mexican researchers reported that during the use of VIUSID vet powder in feed for fattening pigs, the defences of the organisms improved, which is measured through a haemagglutination inhibition test and real RT-PCR for Swine Influenza Virus subtypes H1N1 and H3N2 [16].

As research conducted with the product in pigs is still in its infancy, and many of its effects on this species have yet to be studied. However, in humans the antiviral properties of glycyrrhizinic acid have been proven in the hepatitis virus $[17,18]$, in the respiratory syncytial virus [19] and in others, such as HIV [15] and Flavivirus [20, 21].

It has been determined that the mechanism of antiviral action of glycyrrhizinic acid works by inhibiting the replication of the Flaviviruses through the protein phosphorylation of kinase-P [22]. It is also put forward that it can improve this cellular response by enhancing the host's immune response to infection, according to randomized studies [23, 24].

VIUSID also stimulates the production of interleukin-12 in macrophages, facilitating the production of interferons, which promotes the activation of alveolar macrophages and, as a result, increases their destructive and phagocytic properties against microorganisms [25].

Table 1 shows the effect of supplying VIUSID vet powder on the productive behaviour in post-partum sows and their litter. The treatment had a significant influence $(p<0.05)$ on the variables: size of the litter upon weaning (PWL), weight of the litter at farrowing (Initial weight), weight of the litter at weaning (Final weight) and increase in weight. On the other hand, the weaning-fecundation interval (WFI) and body condition (BC) was not affected with regards to the control, despite the treated sows having more numerous and heavier litters.

The piglets born alive through parturition (PBA) in the treated group differed significantly from the control group. Several studies suggest that a critical factor that defines perinatal survival is the farrowing process. The above involves intense physical exertion over a long period of time; this exertion can lead to oxidative stress, which is why substances which have antioxidant properties can reduce the damage done.

VIUSID counteracts the effect of oxidative stress through the reduction of lipid peroxidation products and the immunomodulatory effect of cytokine secretion. An increase in the production of IFN and IL-10, reduced production of IL-1, and stabilized TNF were observed in patients with chronic hepatitis $\mathrm{C}$ [6]. 
Table 1 Effect of VIUSID vet powder on the main productive indicators, post-partum, of sows treated from 21 days before the date of farrowing (mean \pm standard error).

\begin{tabular}{lllll}
\hline Variables & $\mathrm{U} / \mathrm{M}$ & Control & VIUSID vet powder & $\mathrm{P}$ \\
\hline Sows & $\mathrm{U}$ & 35 & 37 & - \\
Initial piglets & $\mathrm{U}$ & 347 & 393 & - \\
End piglets & $\mathrm{U}$ & 310 & 362 & - \\
PBA & $\mathrm{U}$ & $9.91 \pm 0.36$ & $10.62 \pm 0.28$ & 0,047 \\
$\mathrm{SPL}$ & $\mathrm{U}$ & $0.48 \pm 0.12$ & $0.27 \pm 0.10$ & 0,167 \\
PWL & $\mathrm{U}$ & $8.85 \pm 0.29$ & $9.78 \pm 0.26$ & 0.023 \\
Initial weight & $\mathrm{kg}$ & $14.25 \pm 0.43$ & $15.43 \pm 0.42$ & 0.047 \\
Final weight & $\mathrm{kg}$ & $74.13 \pm 2.73$ & $86.72 \pm 2.50$ & 0.001 \\
Increase in weight & $\mathrm{kg}$ & $59.88 \pm 2.44$ & $71.29 \pm 2.34$ & 0.001 \\
WFI & $\mathrm{days}$ & $4.40 \pm 0.84$ & $5.54 \pm 0.72$ & 0.305 \\
BC & - & $3.15 \pm 0.05$ & $3.12 \pm 0.04$ & 0.611 \\
Increase improvement & $\%$ & 0 & 19.05 & - \\
\hline
\end{tabular}

The improved weight increase per litter, approximately $19 \%$ with regards to the control group, due to a higher number of weaned piglets, approximately one piglet more per farrowing (PWL), and the higher average weight of the same, 500 grams per pig, all due to the improved behaviour of mortality and diarrhoeas.

In previous research with calved sows, 10 grams of VIUSID vet powder was received from the first day after giving farrowing and up to weaning (26 days), significantly improved $(\mathrm{p}<0.05)$ in the end weight and final litter weight variables [26, 27].

Another trial in sows, with a dosage of 1 gram and 2 grams of VIUSID vet powder per $\mathrm{kg}$ of feed, administered 15 days before farrowing and until weaning, found that administering the 2 grams dosage positively affects the piglets that were born alive, the piglets alive at 21 days and the weight of the litter on weaning [28].

VIUSID also provides folic acid, which increases the size of the litter. A greater response to the supplement has been observed in multiparous sows in comparison to pigs at first or second farrowing, possibly due to the fact that the older animals have a higher ovulation rate and therefore a higher possibility of embryonic mortality. The beneficial effects of folic acid may be caused by its effect on the regulation of the leptin receptor in the embryonic and endometrial tissues. Leptin, apart from its effects on metabolism and food intake, plays an important role in the control of various reproductive functions [29].

No statistically significant reduction $(\mathrm{p}=0.100)$ of mortality was observed in the piglets, although it was lower in the group treated.

\subsection{Results and Discussion of Experiment 2}

The variables being evaluated showed no significant differences at the beginning of the experiment $(\mathrm{p}>0.05)$. Table 2 shows the results obtained in the second evaluation, two weeks after discontinuing VIUSID vet powder. Only the variable Spermatic motility differed statistically $(\mathrm{p}=0.002)$, which was higher in treated boars by $4.5 \%$, showing similar values in the samples from treated animals, evidenced by the coefficient of variation obtained $(4.44 \%)$. The experimental error was that it was low in all the variables, which confirms high accuracy in measurements and observations made. Normal sperm (\%), Pathological sperm (\%) and Colour and odour of semen did not differ either, and were within the range considered normal in Cuba [10].

Table 3 shows the results in 14 weeks after the beginning of the experiment, 8 weeks after concluding the administration of VIUSID vet powder. As in the previous evaluation, no statistically significant differences were observed $(p>0.05)$ in the variables 
Table 2 Effect of VIUSID vet powder on the quality of semen, at 8 weeks from the start (mean \pm standard error).

\begin{tabular}{lllll}
\hline Variables & $\mathrm{U} / \mathrm{M}$ & Control & Treatments & $\mathrm{P}$ \\
\hline $\mathrm{N}$ & $\mathrm{u}$ & 12 & 12 & \\
Volume & $\mathrm{mL}$ & $211.83 \pm 3.63$ & $212.41 \pm 3.72$ & 0.912 \\
Concentration & $10^{6} \mathrm{spz} / \mathrm{mL}$ & $181.00 \pm 1.76$ & $177.00 \pm 1.53$ & 0.101 \\
Motility & $\%$ & $78.83 \pm 1.07$ & $83.33 \pm 0.71$ & 0.002 \\
$\mathrm{pH}$ & - & $6.68 \pm 0.05$ & $6.71 \pm 0.05$ & 0.736 \\
\hline
\end{tabular}

Table 3 Effect of VIUSID vet powder on the quality of semen, at the end of the experiment, 14 weeks (mean \pm standard error).

\begin{tabular}{lllll}
\hline Variables & $\mathrm{U} / \mathrm{M}$ & Control & Treatments & $\mathrm{P}$ \\
\hline $\mathrm{N}$ & $\mathrm{u}$ & 12 & 12 & \\
Volume & $\mathrm{mL}$ & $213.66 \pm 3.61$ & $214.16 \pm 3.68$ & 0.924 \\
Concentration & $10^{6} \mathrm{spz} / \mathrm{mL}$ & $180.83 \pm 1.62$ & $179.33 \pm 1.21$ & 0.467 \\
Motility & $\%$ & $79.42 \pm 0.84$ & $82.92 \pm 0.74$ & 0.005 \\
$\mathrm{pH}$ & - & $6.68 \pm 0.05$ & $6.71 \pm 0.05$ & 0.736 \\
\hline
\end{tabular}

under study, except Spermatic motility, that continued to show statistically greater behaviour in the treated boars $(\mathrm{p}=0.005)$.

The effect on motility, which indicates the movement capacity of the spermatozoa, is due to their improved nutrition, because VIUSID provides amino acids, minerals, vitamins and organic acids. In addition, the molecular activation increases its antioxidant capacity and it is known that cellular activity increases oxidative processes, so the product serves as a protective function in this regard.

There are many minerals and trace elements involved in the reproductive activity of the boar, as it intervenes in both the development and maintenance of the musculoskeletal system and weight, and in the production and stability of sperm. Usually, the same amounts of food are provided for boars and for breeding sows, but it would be interesting to pay some attention to certain trace elements, for example:

The lack of zinc in boars is linked to atrophy of the testicles and the seminiferous epithelium with a reduction in the weight of the prostate and the epididymis, as well as the number of Leydig cells; it also intervenes in spermatogenesis, in the luteinizing humoral response and in the formation of steroids [30].

$\mathrm{Zn}$ also influences the stability of the sperm membranes and the consumption of oxygen in the sperm [31].

Zinc is an important trace mineral that, together with the copper, which is needed by the pig for many metabolic functions [32]. Most enzymes in pigs require zinc in their structure to function normally; it is an essential part of insulin. Pigs with deficient levels of zinc show poor growth, poor appetite and parakeratosis [33]. VIUSID vet Powder contains 0.23\% Zn sulphate.

The majority of the fat-soluble vitamins and some water-soluble ones have a decisive role in the reproductive function of the boar [30].

Other trials prove that supplementing with arginine in the diet stimulates protein synthesis in the skeletal muscles of pigs $[34,35]$. There is growing evidence that arginine has an important role in the regulation of energy metabolism [36].

Although this experiment only evaluated the quality of the semen, VIUSID must also have influenced the nutritional status of the boars. In an experiment with sows in development, weighing between $40 \mathrm{~kg}$ and 85 $\mathrm{kg}$, it was found that VIUSID vet powder significantly improved $(\mathrm{p}<0.05)$ weight increase $(45.78 \mathrm{~kg}$ vs $48.85 \mathrm{~kg})$, mean daily gain $(0.654 \mathrm{~kg}$ vs $0.698 \mathrm{~kg})$, feed conversion (3.91 vs 3.66), hematocrit and plasma protein [37]. 


\section{Conclusions}

VIUSID vet powder, used as a nutritional supplement in sows from 21 days before the probable date of farrowing until weaning, significantly improved the principal post-partum productivity indicators and significantly reduced diarrhoea. Administration to boars in production for 6 weeks has improved spermatic motility and does not affect the other variables representative of the quality of the semen.

\section{References}

[1] Quiles, A. J., and Hevia, M. L. 1997. "Handling of Pigs during Parturition.” Revista Agropecuaria 781: 642-47. (in Spanish)

[2] Martín, S., Martínez, E., García, C., and De Alba, C. 1999. "Boar Semen. Practical Assessment." Archivos de Reproducción Animal (ARA). 1:122-23. (in Spanish)

[3] Diedrich, P., Rempel, C., Cunha, I., and da Silva, A. 2014. "Nutritional Supplementation in Boars with Low Production of Semen Doses." Revista Brasileira de Higiene e Sanidade Animal 8 (3): 160-72. (in Portuguese)

[4] Ortwin, S. 2005. "Microorganisms as Feed Additives-Probiotics." Advances in Pork Production 16: 161.

[5] Tanaka, Y. 2001. "Antibacterial Compounds of Licorice against Upper Airway Respiratory Tract Pathogens." $J$. Nutr. Sci. Vitaminol. 47 (3): 270-73.

[6] Vilar, E., Martínez, Y., Vega, H., Arus, E., Calzadilla, L., Yasells, A., et al. 2010. "Antioxidant and Immunomodulatory Effects of VIUSID in Patients with Chronic hepatitis C." World J. Gastroenterol 16 (21): 2638-47.

[7] Brooks, P. H., and Cole, D. I. A. 1992. "The Effect on Litter Size of Increased Feed Intake during the Asters Period in the Sow." Animal Production 14 (2): 241-45.

[8] MINITAB. 2003. Statistical Software Minitab Release 14.12.0. Pennsylvania, USA: Minitab Inc..

[9] SPSS. 2006. Statistical Package for the Social Sciences (SPSS), versión 15.0.1. Chicago, USA: SPSS Inc..

[10] Macías, M., Domínguez, P. L., Abeledo, C. M., Sosa, R., García, A., Cruz, E., et al. 2015. Technical Procedures Manual for the Pig Industry. La Habana: EDIPORC. (in Spanish)

[11] Mateu, E. 2005. "Infant and Weaned Piglet Digestive Immunity." 3tres3. Accessed November 14, 2014. http://www.3tres3.com/diarreas/inmunidad-digestiva-dellechon-lactante-y-destetado_1305/.
[12] Rodríguez, J. C., Calero. I., Méndez, V., and Peña, K. 2016. "Effect of the Dietary Supplement VIUSID Vet, on the Productive Behavior of Newly Weaned Pigs." In Proceedings of the 24th International Pig Veterinary Society Congress and 8th European Symposium of Porcine Health Management, 639.

[13] Le Treut, Y. 2006. "Feed and Nutrition of Pregnant Sows." 3tres3. Accessed January 20, 2015. https://www.3tres3.com/alimentacion_cerda/alimentacion -y-nutricion-de-la-cerda-gestante-i_1588/.

[14] Ito, M., Sato, A., and Hirabayashi, K. 1988. "Mechanism of Inhibitory Effect of Glycyrrhizin on Replication of Human Immunodeficiency Virus (HIV)." Antiviral Res. 10 (6): 289-98.

[15] Baba, M., and Shiget, S. 1987. "Antiviral Activity of Glycyrrhizin against Varicella-zoster Virus in Vitro." Antiviral Res. 7 (2): 99-107.

[16] Ocampo, L., and Sánchez, I. 2012. "Evaluation of the Effectiveness of VIUSID Vet Powder on Productive and Immunological Parameters in Fattening Pigs." Los Porcicultores y su entorno 15 (85): 98-102. (in Spanish)

[17] Takahara, T., Watanabe, A., and Shiraki, K. 1994. "Effects of Glycyrrhizin on Hepatitis B Surface Antigen: a Biochemical and Morphological Study." J. Hepatol. 21 (4): 601-09.

[18] Van Rossum, T. G. J., Vulto, A. G., Hop, W. C. J., Brouwer, J. T., Niesters, H. G. M., and Schalm, S. W. 1999. "Intravenous Glycyrrhizin for the Treatment of Chronic Hepatitis C: a Double-blind, Randomized, Placebo-controlled Phase I/II Trial." J. Gastroenterol. Hepatol. 14 (11): 1093-99.

[19] Wang, X. Q., Li, H. Y., and Liu, X. Y. 2006. "The Anti-respiratory Syncytial Virus Effect of Active Compound of Glycyrrhiza GD4 in Vitro." Zhang Yao Cal. 29 (7): 692-94.

[20] Badam, L. 1997. "In Vitro Antiviral Activity of Indigenous Glycyrrhizin, Licorice and Glycyrrhizic Acid (Sigma) on Japanese Encephalitis Virus." J. Commun. Dis. 29 (2): 91-9.

[21] Crance, J. M., Scaramozzino, N., Jouan, A., Garin, D. 2003. "Interferon, Ribavirin, 6-azauridine and Glycyrrhizin: Antiviral Compounds Active against Pathogenic Flaviviruses." Antiviral Res. 58: 73-9.

[22] Ohtsuki, K., and Iahida, N. 1988. "Inhibitory Effect of Glycyrrhizin on Polypeptide Phosphorylation by Polypeptide-dependent Protein Kinase (Kinase P) in Vitro." Biochem. Biophys. Res. Commun. 157 (2): 597-604.

[23] Fiore, C., and Eisenhut, M. 2008. "Antiviral Effects of Glycyrrhiza Species.” Phytother. Res. 22 (2): 141-48.

[24] Hsueh-Hsia, L., and Yee-Sang, Y. 1997. "Glycyrrhizic Acid Inhibits Arylamine N Acetyltransferase Activity in 


\section{Behaviour of Sows and Boars}

Klebsiella Pneumoniae in Vitro." Journal of Applied Toxicology 17 (6): 385-90.

[25] Di Mambro, V. M., and Fonseca, M. J. V. 2005. “Assays of Physical Stability and Antioxidant Activity of a Topical Formulation Added with Different Plant Extracts." J. Pharm. Biomed. Anal. 37 (2): 287-95.

[26] Rodríguez, J. C., Méndez, V., Calero, I., Peña, K., Bernal, Y., Marín, R., et al. 2015. "Effect of Supplying a Molecularly Activated Nutritional Supplement to Calved Sows." In Proceedings of the VI International Seminar Porcicultura Tropical 2015, 20-24. (in Spanish)

[27] Rodríguez, J. C., Calero, I., Méndez, V., and Peña, K. 2016. "Effect of the Nutritional Supplement VIUSID Vet, on the Productive Behavior of Lactating Sows and Their Piglets." In Proceedings of the 24th International Pig Veterinary Society Congress and 8th European Symposium of Porcine Health Management, 638.

[28] Rodríguez, J. C., Méndez, V., Calero, I., Suarez, L., Marín, R., Bernal, Y., et al. 2014. "Effect of Supplying VIUSID Vet Powder on the Productive Behaviour in Post-partum Sows." In Proceedings of the XXIV Panamerican Congress of Veterinary Sciences, 6-9. (in Spanish)

[29] Pig International. 2002. "Impact of Vitamin Levels during the Reproductive Cycle: Pre-mount, Ovulation and Fertilization and Start of Gestation.” Pig International 32 (10): 34-41.

[30] Quiles, A. J. M. 2008. "Factors that Affect the Fertility of the Boar." Ediporc 115: 30-39. (in Spanish)
[31] Rioperez, J. 1994. "The Nutrition of Breeding Pigs.II Vitamins and Minerals." Revista Mundo Ganadero 9: $42-45$.

[32] Jacela, J. Y., De-Rouchey, J. M., Tokach, M. D., Goodband, R. D., Nelssen, J. L., Renter, D. G., et al. 2010. "Feed Additives for Swine: Fact Sheets-High Dietary Levels of Copper and Zinc for Young Pigs, and Phytase." J. Swine Health Prod. 18 (2): 87-91.

[33] The Pig Site. 2014. "Pig Health." Zinc. Accessed January 18 , 2015. http://www.thepigsite.com/pighealth/article/546/zinc.

[34] Kim, S. W., and Wu, G. 2004. "Dietary Arginine Supplementation Enhances the Growth of Milk-fed Young Pigs." J. Nutr. 134 (3): 625-30.

[35] Yao, K., Deng, D., Liu, Z. Q., Li, T. J., Huang, R. L., Chu, W. Y., et al. 2008. "Dietary Arginine Supplementation Increases Intracellular Mtor Signaling Activity in Skeletal Muscle of Neonatal Pigs.” J. Nutr. 138 (5): 867-72.

[36] Jobgen, W. S., Fried, S. K., Fu, W. J., Meininger, C. J., and Wu, G. 2006. "Regulatory Role for the Arginine-nitric Oxide Pathway in Metabolism of Energy Substrate." J. Nutr. Biochem. 17 (9): 571-88.

[37] Rodríguez, J. C., Calero, I., Méndez, V., and Peña, K. 2016. "Effect of the Nutritional Supplement VIUSID Vet on the Productive Behavior and the Hemogram of Replacement Sows." In Proceedings of the 24th International Pig Veterinary Society Congress and 8th European Symposium of Porcine Health Management, 655. 